\title{
Acute Severe Hyponatremia Induced by a Duloxetine Overdose in an Elderly Woman
}

\author{
Wesley D. Oliver ${ }^{1}$, Ryan D'Angelo ${ }^{2}$, Jeffrey Gonzales ${ }^{3}$, Tracey Wilson ${ }^{4}$, Leah S. Millstein ${ }^{5}$ \\ 1. Emergency Medicine, University of Maryland Medical Center, Baltimore, USA 2. Cardiology, Thomas Jefferson \\ University Hospital, Philadelphia, USA 3. Internal Medicine: Critical Care, None, Baltimore, USA 4. Medical Intensive \\ Care Unit, University of Maryland Medical Center, Baltimore, USA 5. Internal Medicine - Pediatrics, University of \\ Maryland School of Medicine, Baltimore, USA
}

Corresponding author: Wesley D. Oliver, woliver@umm.edu

\begin{abstract}
We report a case of acute severe hyponatremia within 24 hours after a duloxetine overdose. An 82-year-old woman presented to the ED after ingesting duloxetine and diltiazem. She became hemodynamically unstable due to the diltiazem overdose and was appropriately resuscitated. During hospitalization she experienced hyponatremia consistent with syndrome of inappropriate antidiuretic hormone (SIADH). Based on the observations we concluded there was a probable relationship between the hyponatremia and the duloxetine overdose. Clinicians should monitor patients' electrolytes for acute disturbances after an overdose of duloxetine.
\end{abstract}

Categories: Endocrinology/Diabetes/Metabolism, Emergency Medicine, Internal Medicine

Keywords: duloxetine, hyponatremia, overdose, syndrome of inappropriate antidiuretic hormone secretion

\section{Introduction}

Hyponatremia (serum sodium level $<136 \mathrm{mmol} / \mathrm{L}$ ) is a common electrolyte imbalance encountered in the hospital setting. Patients are often asymptomatic and resolution typically occurs with minimal intervention. Symptomatic hyponatremia, characterized by headache, vomiting, lethargy, altered mental status, necessitates more aggressive therapy to prevent seizure, coma, and death [1].

Hyponatremia is a well-documented adverse effect of chronic administration of selective serotonin reuptake inhibitors (SSRIs) and selective serotonin and norepinephrine reuptake inhibitors (SNRIs) [2-6]. The most likely cause of hyponatremia in these patients is the syndrome of inappropriate antidiuretic hormone (SIADH), which is characterized by euvolemia, low serum osmolality ( $<275 \mathrm{mOsm} / \mathrm{kg}$ of water), elevated urine osmolality (>100 mOsm/kg of water), and a urine sodium greater than $40 \mathrm{mmol} / \mathrm{L}$. Treatment of SIADH-associated hyponatremia ranges from fluid restriction in asymptomatic patients to IV hypertonic saline in symptomatic patients [7-8].

Received 06/15/2020

Review began 06/23/2020 Review ended 08/27/2020 Published 09/08/2020

\section{(c) Copyright 2020}

Oliver et al. This is an open access article distributed under the terms of the Creative Commons Attribution License CC-BY 4.0., which permits unrestricted use, distribution, and reproduction in any medium, provided the original author and source are credited.
There are multiple reports of patients developing hyponatremia upon initiation or while taking chronic duloxetine [7-18]. We present a case of acute severe hyponatremia due to an overdose of duloxetine, which has not been previously described.

\section{Case Presentation}

An 82-year-old Caucasian woman, weighing $70.5 \mathrm{~kg}$ and $160 \mathrm{~cm}$ tall, being treated with duloxetine for depression presented to the ED within one hour of ingesting approximately 15 duloxetine $30 \mathrm{mg}$ capsules (450 mg) and the same number of extended-release diltiazem $120 \mathrm{mg}$ tablets. The patient became hemodynamically unstable in the ED due to the quantity of diltiazem prompting treatment with activated charcoal, calcium gluconate, normal saline, intralipids, and high-dose insulin euglycemic therapy. During this period of time the patient received two liters of normal saline, one liter of dextrose $10 \%$, and one liter of dextrose $20 \%$ as part of the high-dose insulin euglycemic therapy. The patient's hemodynamic instability due to the diltiazem overdose was appropriately treated.

The patient's medical history was significant for depression, hypertension, and hyperlipidemia. She reported previous allergic reactions to sulfa with an unknown manifestation. Home medications included duloxetine $30 \mathrm{mg}$ orally daily, diltiazem extended-release $120 \mathrm{mg}$ orally daily, and atorvastatin $40 \mathrm{mg}$ orally daily. During the two months prior to this incident, the patient was taking duloxetine and had two sodium results of 138 and $140 \mathrm{mmol} / \mathrm{L}$, which were presumed to be her baseline levels. It is unknown how long the patient had been taking duloxetine prior to this two month period.

The patient's admission sodium level was $133 \mathrm{mmol} / \mathrm{L}$ (normal range: $136-145 \mathrm{mmol} / \mathrm{L}$ ) and serum osmolality was $280 \mathrm{mOsm} / \mathrm{kg}$ (normal range: $275-295 \mathrm{mOsm} / \mathrm{kg}$ ) [7-8]. During day 2 of hospitalization, the serum sodium decreased to $122 \mathrm{mmol} / \mathrm{L}$. The hyponatremia was conservatively managed with fluid 
restriction of $1,000 \mathrm{~mL} /$ day and diuresis. In an effort to continue management of her psychiatric disease, the patient received a dose of duloxetine on hospital day 3 and day 4 . During day 4 , the serum sodium reached a nadir of $118 \mathrm{mmol} / \mathrm{L}$.

On day 5 of hospitalization, urine tests revealed an increased urine osmolality of $354 \mathrm{mOsm} / \mathrm{kg}$ (diagnostic if $>100 \mathrm{mOsm} / \mathrm{kg}$ ) and an increased urine sodium of $113 \mathrm{mmol} / \mathrm{L}$ (diagnostic if $>40 \mathrm{mmol} / \mathrm{L}$ ), consistent with SIADH [7-8]. The patient's sodium slowly increased to $133 \mathrm{mmol} / \mathrm{L}$ on day 10 . See Figure 1 for the trend of sodium levels during hospital admission.

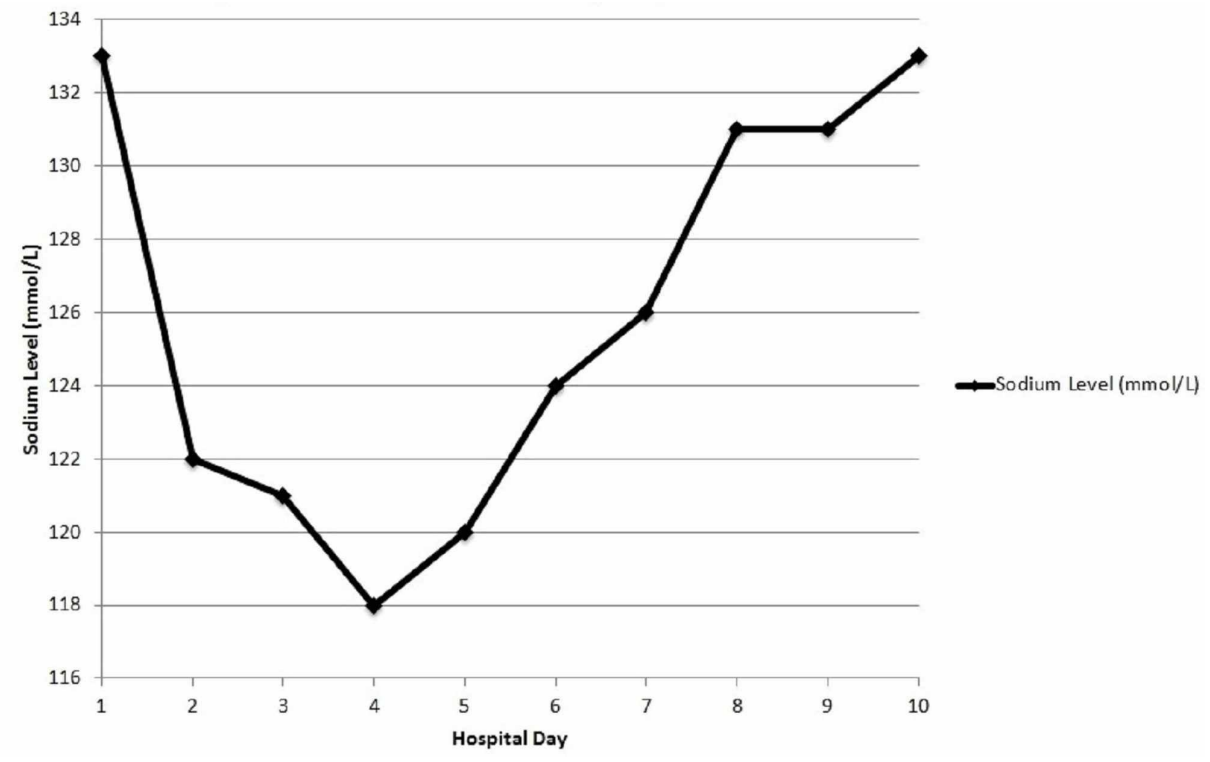

FIGURE 1: Sodium levels during hospital admission.

Note: The patient had a baseline sodium of $140 \mathrm{mmol} / \mathrm{L}$ approximately two months before admission.

Alternate etiologies of hyponatremia, such as adrenal, thyroid, and renal disease, were excluded during this admission. The patient was ultimately transferred to a psychiatric floor after being medically cleared and subsequently discharged home.

\section{Discussion}

Our patient developed hyponatremia within 24 hours of ingesting a large amount (estimated $450 \mathrm{mg}$ ) of duloxetine and diltiazem. To our knowledge, this is the first documented report of acute severe hyponatremia in the setting of a duloxetine overdose.

There are many potential causes for hyponatremia in the elderly population; thus, alternate etiologies, such as adrenal, thyroid, and renal disease, were excluded during this admission. No other risk factors for hyponatremia in this patient were identified. Use of the Naranjo Adverse Drug Reaction Probability Scale indicated a probable relationship between the adverse effect of hyponatremia and the duloxetine overdose in this patient, which is consistent with our conclusion that duloxetine is the likely cause of hyponatremia [19].

Duloxetine-induced hyponatremia is thought to be caused by the induction of SIADH. It has been suggested that both norepinephrine and serotonin can stimulate antidiuretic hormone (ADH) secretion and duloxetine inhibits the reuptake of both; however, the exact mechanism of duloxetine-induced SIADH has not been elucidated $[2,13]$.

Duloxetine exhibits a half-life of up to 17 hours, thus resolution of hyponatremia could be expected over four to five days [20]. Our patient reached a nadir of $118 \mathrm{mmol} / \mathrm{L}$ on day 4 of hospitalization; however, administration of additional duloxetine doses on days 3 and 4 of hospitalization and the large overdose of duloxetine $(450 \mathrm{mg}$ ) prior to admission may have prolonged stabilization to seven days. Previous reports have documented hyponatremia within two to five days after initiating duloxetine or after a dose escalation on chronic duloxetine therapy, but have not demonstrated a case this severe and abrupt in the setting of an overdose [7, 9-18]. 
sodium decreased to $118 \mathrm{mmol} / \mathrm{L}$ approximately six days after admission and she was diagnosed with SIADH. After discontinuing duloxetine, the patient's serum sodium increased to $130 \mathrm{mmol} / \mathrm{L}$ after three days [7].

Choi et al. described a 58-year-old male being treated with duloxetine for somatic and depressive symptoms. The patient was started on duloxetine $30 \mathrm{mg}$ daily, which was increased to $60 \mathrm{mg}$ daily five days after initiation. The patient's initial sodium was $135.1 \mathrm{mmol} / \mathrm{L}$; however, six days after initiation of duloxetine the serum sodium decreased to $122 \mathrm{mmol} / \mathrm{L}$. The patient was subsequently diagnosed with SIADH and duloxetine was discontinued. The serum sodium level normalized to $135.4 \mathrm{mmol} / \mathrm{L}$ two days after discontinuation [9].

$\mathrm{Hu}$ and Wurster reported an 81-year-old female who was started on duloxetine $30 \mathrm{mg}$ daily for mood stabilization. The patient developed hyponatremia with a sodium of $120 \mathrm{mmol} / \mathrm{L}$ after two doses of duloxetine. The patient's baseline sodium level was $131 \mathrm{mmol} / \mathrm{L}$. The patient was diagnosed with SIADH, the medication was discontinued by the ED physician, and the patient was instructed to follow-up with the outpatient provider [10].

Kulkarni described a 38-year-old female who was started on duloxetine for generalized anxiety disorder. After four days of therapy she was found to have a serum sodium of $117 \mathrm{mmol} / \mathrm{L}$. Duloxetine was stopped and her serum sodium improved to $138 \mathrm{mmol} / \mathrm{L}$ after five days. Two weeks later duloxetine was restarted and her serum sodium was $124 \mathrm{mmol} / \mathrm{L}$ after two days. Serum sodium levels returned to normal after duloxetine was discontinued the second time [12].

Mori et al. reported an 86-year-old female who was started on duloxetine $20 \mathrm{mg}$ daily and trichlormethiazide $2 \mathrm{mg}$ daily six days prior to hospital admission. Upon admission she was found to have a serum sodium level of $116 \mathrm{mmol} / \mathrm{L}$ and she was diagnosed with SIADH. The medications were discontinued and she was treated with fluid restriction, diuretics, and oral sodium chloride. Serum sodium increased to $123 \mathrm{mmol} / \mathrm{L}$ on the third day of admission and further increased to $137 \mathrm{mmol} / \mathrm{L}$ on the seventh day of admission, after which therapies were stopped [13].

Sun et al. presented a case of a 68-year-old male with major depressive disorder who developed hyponatremia one month after initiating duloxetine $30 \mathrm{mg}$ daily. The patient was admitted to the hospital with complaints of unsteady gait, dizziness, nausea, malaise, decreased oral intake, and insomnia. His initial sodium of $130 \mathrm{mmol} / \mathrm{L}$ subsequently decreased to $127 \mathrm{mmol} / \mathrm{L}$ on day six of the hospital admission. The patient's baseline sodium was noted to be $137 \mathrm{mmol} / \mathrm{L}$. The patient was diagnosed with SIADH and duloxetine cross-titrated to escitalopram. The patient's hyponatremia resolved approximately eight days after discontinuing duloxetine [15]

Wang et al. reported a 78-year-old who developed hyponatremia and delirium after taking two doses of duloxetine $60 \mathrm{mg}$ daily for postherpetic neuralgia. The initial sodium was $125 \mathrm{mmol} / \mathrm{L}$. Duloxetine was discontinued and within one week the patient's sodium returned to normal [16].

Yang and Wu described a 57-year-old female with major depressive disorder treated with duloxetine. The patient was initiated on duloxetine $30 \mathrm{mg}$ daily and after three weeks with no improvement in symptoms the dose was increased to $60 \mathrm{mg}$ daily. Three days after the dose escalation the patient was found to have a serum sodium of $114 \mathrm{mmol} / \mathrm{L}$ and was diagnosed with SIADH. Duloxetine was discontinued and the patient was treated with fluid restriction, hypertonic saline, and diuretics. The serum sodium increased to 130 $\mathrm{mmol} / \mathrm{L}$ after three days [17].

Yoshida et al. described a 77-year-old female who developed hyponatremia after a single dose of duloxetine. Upon admission her sodium was $119 \mathrm{mmol} / \mathrm{L}$, with her baseline being $135 \mathrm{mmol} / \mathrm{L}$ one day prior. The hyponatremia resolved after two days [18].

A potential contributing factor to our patient's hyponatremia could have been the fluids used during the first 24 hours. These fluids were used during high-dose insulin euglycemic therapy for the diltiazem overdose and there are no documented reports of hyponatremia or development of SIADH during this therapy; thus, it is unlikely that the administration of these fluids contributed to the observed hyponatremia.

\section{Conclusions}

We report the first documented case of acute severe hyponatremia from an overdose of duloxetine in a patient previously stable on an appropriate chronic dose. Given the time of onset of hyponatremia, diagnosis of SIADH, and time course to resolution, it is probable that the overdose of duloxetine is the cause of hyponatremia in this patient. Given the nature of this case, clinicians should monitor patients' electrolytes for acute disturbances after an overdose of duloxetine. 


\section{Additional Information \\ Disclosures}

Human subjects: Consent was obtained by all participants in this study. Conflicts of interest: In compliance with the ICMJE uniform disclosure form, all authors declare the following: Payment/services info: All authors have declared that no financial support was received from any organization for the submitted work. Financial relationships: All authors have declared that they have no financial relationships at present or within the previous three years with any organizations that might have an interest in the submitted work. Other relationships: All authors have declared that there are no other relationships or activities that could appear to have influenced the submitted work.

\section{References}

1. Sterns RH: Disorders of plasma sodium-causes, consequences, and correction . N Engl J Med. 2015, 372:5565. 10.1056/NEJMra1404489

2. Kirby D, Ames D: Hyponatraemia and selective serotonin re-uptake inhibitors in elderly patients . Int J Geriatr Psychiatry. 2001, 16:484-493. 10.1002/gps.367

3. Liu BA, Mittmann N, Knowles SR, Shear NH: Hyponatremia and the syndrome of inappropriate secretion of antidiuretic hormone associated with the use of selective serotonin reuptake inhibitors: a review of spontaneous reports. Can Med Assoc J. 1996, 155:1043.

4. Jacob S, Spinler SA: Hyponatremia associated with selective serotonin-reuptake inhibitors in older adults . Ann Pharmacother. 2006, 9:1618-1622. 10.1345/aph.1G293

5. Viramontes TS, Truong H, Linnebur SA: Antidepressant-induced hyponatremia in older adults. Consult Pharm. 2016, 31:139-150. 10.4140/TCP.n.2016.139

6. Movig KL, Leufkens HG, Lenderink AW, Egberts AC: Serotonergic antidepressants associated with an increased risk for hyponatraemia in the elderly. Eur J Clin Pharmacol. 2002, 58:143-148. 10.1007/s00228002-0438-5

7. Amoako AO, Brown C, Riley T: Syndrome of inappropriate antidiuretic hormone secretion: a story of duloxetine-induced hyponatremia. BMJ Case Rep. 2015, 2015:bcr2014208037. 10.1136/bcr-2014-208037

8. Ellison DH, Berl T: The syndrome of inappropriate antidiuresis . N Engl J Med. 2007, 356:2064-2072. 10.1056/NEJMcp066837

9. Choi JS, Lee HW, Lee JY, Jung HY: Rapid-onset hyponatremia induced by duloxetine in a middle-aged male with depression and somatic symptoms. Psychiatry Investig. 2012, 9:83-84. 10.4306/pi.2012.9.1.83

10. Hu D, Wurster S: Hyponatremia induced by duloxetine. Consult Pharm. 2018, 33:446-449. 10.4140/TCP.n.2018.446

11. Kruger S, Lindstaedt M: Duloxetine and hyponatremia: a report of 5 cases . J Clin Psychopharmacol. 2007, 27:101-104. 10.1097/JCP.0b013e31802e688a

12. Kulkarni M: Duloxetine induced hyponatremia. Indian J Nephrol. 2015, 25:259. 10.4103/0971-4065.151352

13. Mori M, Koide T, Imanishi Y, Matsui Y, Matsuda T: Duloxetine-induced hyponatremia in an elderly patient treated with thiazide diuretics. Indian J Pharmacol. 2014, 46:657-659. 10.4103/0253-7613.144947

14. Safdieh JE, Rudominer R: A case of hyponatremia induced by duloxetine . J Clin Psychopharmacol. 2006, 26:675-676. 10.1097/01.jcp.0000246207.73034.96

15. Sun CF, Chen YL, Li YH, Kumaraswamy M, Lo YC, Chen YT: Duloxetine-induced hyponatremia in an elderly male patient with treatment-refractory major depressive disorder. Case Rep Psychiatry. 2019, 2019:4109150. $10.1155 / 2019 / 4109150$

16. Wang D, Lai J, Lu S, Huang M, Hu S, Xu Y: Rapid-onset hyponatremia and delirium following duloxetine treatment for postherpetic neuralgia. Medicine. 2018, 97:46. 10.1097/MD.0000000000013178

17. Yang SJ, Wu PL: Severe hyponatremia and syndrome of inappropriate secretion (SIADH) induced by duloxetine. Tzu Chi Med J. 2012, 24:22-23.

18. Yoshida K, Aburakawa Y, Suzuki Y, Kuroda K, Kimura T: Acute hyponatremia resulting from duloxetineinduced syndrome of inappropriate antidiuretic hormone secretion. Intern Med. 2019, 58:1939-1942. 10.2169/internalmedicine.2346-18

19. Naranjo CA, Busto U, Sellers EM, et al.: A method for estimating the probability of adverse drug reactions . Clin Pharmacol Ther. 1981, 30:239-245. 10.1038/clpt.1981.154

20. Cymbalta [package insert]. Indianapolis, IN. Lilly USA, LLC . (2004). Accessed: May 1, 2020: http://pi.lilly.com/us/cymbalta-pi.pdf. 